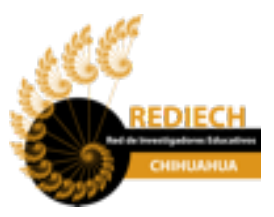

Red de Investigadores Educativos Chihuahua A.C. Chihuahua, México www.rediech.org

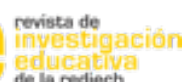

de la rediech

ISSN: 2007-4336

ISSN-e: 2448-8550

http://www.rediech.org/ojs/2017/index.php/ie rie rediech/index

Juan Carlos López García

2019

\title{
EL CONGRESO COMO OBJETO DE ESTUDIO. ANÁLISIS DE COAUTORÍAS DEL CONGRESO DE INVESTIGACIÓN EDUCATIVA EN CHIHUAHUA, 2016 Y 2018
}

IE Revista de Investigación Educativa de la REDIECH, 10(19), pp. 155-171.

DOI: http://dx.doi.org/10.33010/ie_rie_rediech.v10i19.648

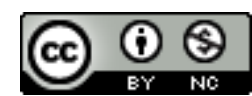

Esta obra está bajo licencia internacional Creative Commons Reconocimiento-NoComercial 4.0.

CC BY-NC 4.0 


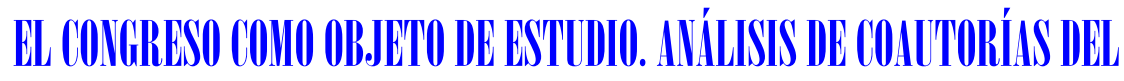

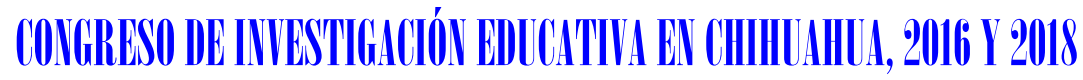

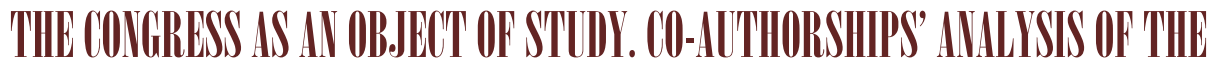

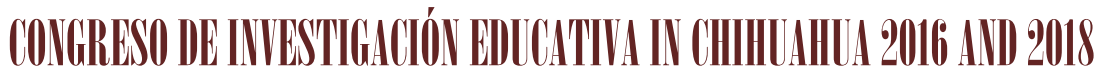

\section{LÓPEZ GARCÍA Juan Carlos}

Recepción: marzo 11 de 2019 | Aprobado para publicación: agosto 8 de 2019

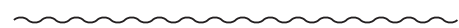

DOI: http://dx.doi.org/10.33010/ie_rie_rediech.v10il 9.648

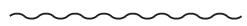

\section{Resumen}

El artículo hace del Congreso de Investigación Educativa en Chihuahua (CIECH) su objeto de estudio. En primer lugar, se apuntan algunos aspectos sobre comunidades académicas en el campo de la investigación educativa (IE). Posteriormente, se utilizan técnicas del análisis de redes sociales (ARS) para establecer las relaciones entre autores a partir de sus coautorías y las relaciones interinstitucionales a que da lugar su afiliación institucional. Se muestran los actores con mayor grado de centralidad en la red de autores, las relaciones de coautoría más intensas y los principales vínculos interinstitucionales. Finalmente, se constata una tensión entre estos últimos y los lazos endogámicos (coautoría entre autores adscritos a la misma institución), lo que plantea la idea de que las comunidades académicas de la IE del estado de Chihuahua están permanentemente tensionadas entre dinámicas centrífugas y centrípetas referidas por Burton Clark.

Palabras clave: INVESTIGACIÓN EDUCATIVA, ANÁLISIS DE REDES,
CONGRESOS ACADÉMICOS.

Juan Carlos López García. Profesor-investigador del Departamento de Estudios Culturales de la Universidad Autónoma Metropolitana Lerma, Toluca, Estado de México. Es sociólogo y maestro en Estudios Políticos y Sociales por la Universidad Nacional Autónoma de México. Miembro del Consejo Mexicano de Investigación Educativa (Comie). Ha colaborado como docente e investigador en distintos proyectos e instituciones de educación superior. Sus líneas de investigación son: internacionalización y endogamia de los académicos mexicanos, redes y comunidades académicas en el campo de la investigación educativa en México, políticas de evaluación en la educación superior y gobierno universitario. Correo electrónico: j.lopezg@correo.ler.uam.mx. ID: http://orcid.org/0000-0002-4815-3116. 


\begin{abstract}
The Educational Research Congress in Chihuahua (CIECH) has been taken as the object of study in this article. First, some aspects about academic communities in the educational research field are pointed out. Afterwards, some Social Network Analysis (SNA) techniques are used in order to set the relationships among authors according to their co-authorships and the interinstitutional relationships based on the institutional affiliation of authors. The actors with the most degree of centrality in the authors' network, the most intense co-authorships' relations and the principal interinstitutional links are shown. Finally, a strain between interinstitutional and inbreed links (co-authorship among authors members of the same institutions) is observed, which raises the Clark's idea of a permanent straining between centrifugal and centripetal forces.
\end{abstract}

Keywords: EDUCATIONAL RESEARCH, SOCIAL NETWORK ANALYSIS, ACADEMIC CONGRESS.

\title{
IITremorcuín
}

Este artículo hace de un congreso académico, el Congresos de Investigación Educativa en Chihuahua (CIECH), su objeto de estudio. Su relevancia estriba en que aporta al conocimiento de cómo la agregación de decisiones individuales - escribir una ponencia con unos pares, y no con otros- devela la conformación de grupos (clústeres) en el ámbito de la investigación educativa (IE) estatal, así como patrones de relación entre instituciones y situaciones de "endogamia académica" que, según parece, remiten a tensiones entre las dinámicas centrífugas y centrípetas referidas por Clark (1991).

En la primera parte se aborda de manera sucinta la discusión sobre las comunidades académicas en la IE en México: su reconfiguración en el tiempo y algunas de sus características organizativas. La segunda parte presenta algunos datos estadísticos sobre el congreso en cuestión: contribuciones recibidas, porcentajes de aceptación, perfil de los congresistas y contribuciones individuales y en coautoría. La tercera parte muestra los resultados de la investigación. Partiendo de las colaboraciones en coautoría, se traza una red de autores y de las instituciones a las que se afilian con miras a identificar los principales grupos en el ámbito de la investigación educativa en el estado de Chihuahua.

Finalmente, el artículo forma parte de un proyecto más amplio cuyo objetivo es generar un enfoque relacional en torno a la IE en México. Ciertamente, conocer cuántos investigadores educativos hay, cuál es su perfil (edad, distribución por sexo, grado máximo de estudios, etcétera) y en qué áreas del conocimiento se agrupan contribuye al conocimiento de las dimensiones y prioridades del campo (véase Ramírez y Weiss, 2004; OECD-CERI, 2004). No obstante, es necesario poner en marcha instrumentos que, además de incorporar ese saber acumulado en torno a la IE, también

156 generen aproximaciones acordes con las nuevas condiciones del trabajo académico 
tal y como se le exige que lleve a cabo hoy en día: articulado en entramados -redescuya extensión va más allá de sus tradicionales límites institucionales y geográficos.

El análisis de redes sociales (ARS), planteo, proporciona esos instrumentos. Y si bien en este artículo se aboca solo a un congreso académico, el CIECH, su estudio arroja elementos de relevancia fundamental para el campo de la IE en su totalidad.

\section{Sobre las comminidades actiadémiciess en lat IE}

Si bien los orígenes de la IE pueden remontarse hasta una suerte de "prehistoria" en la década de los treinta, no será sino hasta los años setenta cuando la creación de instituciones abocadas a la investigación en educación y el incremento del personal calificado para esta tarea permitirá hablar de una "primera consolidación" (Martínez Rizo, 1996), la cual dejaría su impronta en las primeras comunidades de la IE.

Sin embargo, a partir de los noventa, las comunidades experimentarían un importante proceso de reconfiguración al abandonar los anclajes institucionales y disciplinarios que las habían caracterizado hasta entonces para dar lugar a entramados nuevos y con importante presencia en el campo de la IE. Gutiérrez (2009) se referirá a estos como "Comunidades Especializadas en Investigación Educativa", las cuales, pese a las novedades introducidas con respecto a sus predecesoras, continúan manteniendo elementos como la organización de espacios para el intercambio, la reflexión y la producción de conocimiento, así como de los medios para su divulgación. Las revistas especializadas y los congresos académicos suelen ocupar un papel destacado.

Quisiera poder hacer una justificación más extensa de por qué los congresos cobran una relevancia fundamental en el ámbito académico. No obstante, bastará con decir, junto con Larissa Adler (2009), que representan espacios de comunicación entre aspirantes e iniciados, refuerzan los lazos sociales y contribuyen a dar sentido de comunidad a lo que hacemos, aun cuando, si hemos de creer a algunos estudiosos, el nuestro es un espacio fundamentalmente individualista. Hay que tomárselos en serio, escribe la antropóloga, pues lo que se dice y hace durante los congresos tiene total seriedad, aunque no siempre revista este carácter.

Asimismo, a propósito de los "colegios invisibles", Crane (1969) señalaba la necesidad de recurrir a un conjunto de información complementaria para su identificación: tesis asesoradas, comunicaciones informales y participación en congresos.

Comenzaré por enfatizar la importancia de poner en marcha instrumentos que, además de incorporar el saber acumulado en torno a las comunidades y agentes de la IE, también generen aproximaciones acordes con las nuevas condiciones del trabajo académico, tal y como se exige que lleve a cabo hoy en día: articulado en entramados -redes- cuya extensión va más allá de sus tradicionales límites institucionales y geográficos, y en donde, por supuesto, el trabajo colaborativo ocupa un papel fundamental en la producción de conocimiento. El ARS, planteo, proporciona esos instrumentos.

Sin embargo, no me referiré a las comunidades de la IE en el estado de Chihuahua, sino a grupos (clústeres) identificados mediante técnicas específicas del ARS a partir de las coautorías del CIECH. Está claro que el término "comunidad académica" refiere relaciones mucho más ricas y duraderas y no solo las situaciones de colaboración 
en un congreso. Después de todo, veremos, estas no parecen estar exentas de la dimensión coyunturales implicada en eventos de esta naturaleza, haciendo difícil la identificación de comunidades académicas solo mediante procedimientos técnicos.

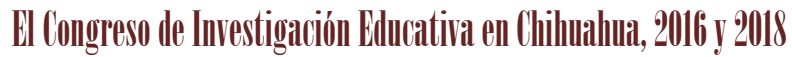

Comenzaré por presentar algunos datos de las últimas dos ediciones del CIECH. Estos fueron proporcionados por los propios autores al momento de registrar su contribución en el Sistema Integral de Gestión de Conocimiento e Información del Comie (Sigecic). Abordaré tres puntos:

1. Contribuciones: su distribución por área, tipo y porcentajes de aceptación.

2. Autores: entidad federativa, afiliación institucional y cargo.

3. Coautoría: porcentaje de contribuciones individuales y colectivas y promedio de autores por contribución.

Luego de abordar al congreso como si se tratase de una cosa, a la manera de Durkheim, me enfocaré en los individuos; pero no en sus atributos, sino en las relaciones que emergen a partir de sus coautorías.

\section{Contribucciones}

Son cuatro los tipos de contribución que se presentan en el CIECH: ponencias, conversaciones educativas, carteles y presentaciones de libro. Cada contribución puede integrarse de hasta tres autores, como veremos más adelante, y se registra en una de las siete áreas del conocimiento del congreso, las cuales, a su vez, están conformadas por subáreas, aunque solo me ocuparé de las primeras (tabla 1).

El CIECH suele aceptar más de la mitad de las contribuciones registradas para su dictaminación. Aunque, como se observa en la tabla 2, tanto el número de contribuciones como el porcentaje global de aceptación disminuyeron de 2016 a 2018.

La mayoría de las contribuciones son ponencias: 76.4\% y 87.94\% del total de las aceptadas en 2016 y 2018, respectivamente. En lo que respecta a las áreas temáticas del CIECH, el área 5, "Procesos de formación y actores de la educación", concentra poco más del 30\% en ambos años. Esta, sin embargo, tampoco ha sido indiferente a los decrementos en el número de contribuciones. Las excepciones a este respecto son las áreas 1 y 7, en las que tanto los registros como las contribuciones aceptadas aumentaron de una edición a otra.

La distribución de las contribuciones según las áreas temáticas resulta pertinente, ya que, veremos, las comunidades de investigación no suelen articularse en función de un criterio temático.

\section{Litores}

Quiénes son los autores que concurren en el CIECH. Más precisamente, de qué países o entidades provienen, a qué instituciones se afilian y cuál es su ocupación prioritaria. Presentaré un cuadro por demás esquemático con el objetivo de mostrar 158 algunos datos que cobrarán sentido a la luz del análisis de redes del siguiente apartado. 


\begin{tabular}{|c|c|}
\hline $\begin{array}{l}\text { 1. Teoría, filosofía, historia y educación e } \\
\text { investigación sobre la investigación educativa }\end{array}$ & $\begin{array}{l}\text { 1.1. Filosofía, teoría y campo de la educación } \\
\text { 1.2. Historia, historiografía de la educación } \\
\text { 1.3. Investigaciones sobre la investigación } \\
\text { educativa }\end{array}$ \\
\hline $\begin{array}{l}\text { 2. Diversidad, interculturalidad, género y } \\
\text { sustentabilidad en la educación }\end{array}$ & $\begin{array}{l}\text { 2.1. Interculturalidad } \\
\text { 2.2. Educación ambiental }\end{array}$ \\
\hline 3.Políticas y gestión de la educación & $\begin{array}{l}\text { 3.1. Políticas educativas } \\
\text { 3.2. Política científica } \\
\text { 3.3. Educación y trabajo } \\
\text { 3.4. Gestión educativa }\end{array}$ \\
\hline 4. Currículo, conocimientos y prácticas educativas & $\begin{array}{l}\text { 4.1. Currículo. } \\
\text { 4.2. Conocimientos disciplinares. } \\
\text { 4.3. Prácticas educativas. }\end{array}$ \\
\hline $\begin{array}{l}\text { 5.Procesos de formación y actores de la } \\
\text { educación }\end{array}$ & $\begin{array}{l}\text { 5.1. Formación } \\
\text { 5.2. Actores }\end{array}$ \\
\hline $\begin{array}{l}\text { 6. Tecnologías de la información y la } \\
\text { comunicación en educación }\end{array}$ & $\begin{array}{l}\text { 6.1. Tecnologías de la información y la } \\
\text { comunicación en educación }\end{array}$ \\
\hline $\begin{array}{l}\text { 7. Valores, convivencia, disciplina y violencia en } \\
\text { la educación }\end{array}$ & $\begin{array}{l}\text { 7.1. Valores } \\
\text { 7.2. Convivencia }\end{array}$ \\
\hline
\end{tabular}

Fuente: Elaboración propia, a partir de la convocatoria del CIECH (Rediech, 2018).

Tabla 2. Contribuciones según área y resultados del proceso de dictaminación, 2016 y 2018.

\begin{tabular}{lccccccccc}
\hline $\begin{array}{l}\text { Área } \\
\text { temá- } \\
\text { tica }\end{array}$ & \multicolumn{4}{c}{$\mathbf{2 0 1 6}$} & \multicolumn{6}{c}{$\mathbf{2 0 1 8}$} & \multicolumn{2}{c}{$\begin{array}{c}\text { Regis- } \\
\text { tradas* }\end{array}$} & $\begin{array}{c}\text { No } \\
\text { acepta- } \\
\text { das }\end{array}$ & $\begin{array}{c}\text { Acepta- } \\
\text { das }\end{array}$ & $\begin{array}{c}\text { \% } \\
\text { acepta- } \\
\text { ción }\end{array}$ & $\begin{array}{c}\text { Regis- } \\
\text { tradas* }\end{array}$ & $\begin{array}{c}\text { No acep- } \\
\text { tadas** }\end{array}$ & $\begin{array}{c}\text { Acep- } \\
\text { tadas }\end{array}$ & $\begin{array}{c}\text { \% } \\
\text { acepta- } \\
\text { ción }\end{array}$ & $\begin{array}{c}\text { Creciento } \\
\text { aceptadas }\end{array}$ \\
\hline AT 01 & 25 & 7 & 18 & 72.00 & 35 & 14 & 21 & 60.00 & 16.7 \\
\hline AT 02 & 37 & 10 & 27 & 72.97 & 17 & 9 & 8 & 47.06 & -70.4 \\
\hline AT 03 & 34 & 8 & 26 & 76.47 & 11 & 3 & 8 & 72.73 & -69.2 \\
\hline AT 04 & 54 & 17 & 37 & 68.53 & 59 & 30 & 29 & 49.15 & -21.6 \\
\hline AT 05 & 99 & 30 & 69 & 69.70 & 72 & 25 & 47 & 65.28 & -31.9 \\
\hline AT 06 & 32 & 14 & 18 & 56.25 & 29 & 15 & 14 & 48.28 & -22.2 \\
\hline AT 07 & 21 & 14 & 7 & 33.33 & 37 & 23 & 14 & 37.84 & 100.0 \\
\hline Total & $\mathbf{3 0 2}$ & $\mathbf{1 0 0}$ & $\mathbf{2 0 2}$ & $\mathbf{6 6 . 8 9}$ & $\mathbf{2 6 0}$ & $\mathbf{1 1 9}$ & $\mathbf{1 4 1}$ & $\mathbf{5 4 . 2 3}$ & $\mathbf{- 3 0 . 2}$ \\
\hline
\end{tabular}

* Contribuciones registradas en el Sistema Integral de Gestión de Conocimiento e Información del Comie (Sigecic). ** Se incluyen contribuciones que fueron rechazadas por cuestiones de forma.

Fuente: elaboración propia, a partir de los datos del Sigecic para las últimas dos ediciones del CIECH (Comie, 2016, 2018).

El CIECH es un congreso fundamentalmente estatal, como puede constatarse en la tabla 3. Más de la mitad de sus ponentes se afilia a alguna institución chihuahuense: $55.12 \%$ y $57.96 \%$ en los dos años aquí analizados. No obstante, aun cuando el resto proviene de otras entidades federativas, la coautoría en las colaboraciones se genera, veremos, entre autores de la misma institución o de instituciones de la misma entidad. 


\begin{tabular}{|c|c|c|c|}
\hline Entidad federativa & 2016 & 2018 & Total \\
\hline Aguascalientes & 3 & 6 & 9 \\
\hline Baja California & 1 & 3 & 4 \\
\hline Baja California Sur & 1 & 2 & 3 \\
\hline Campeche & - & 10 & 10 \\
\hline Chiapas & - & 1 & 1 \\
\hline Chihuahua & 253 & 182 & 435 \\
\hline Ciudad de México & 23 & 22 & 45 \\
\hline Coahuila & 2 & 3 & 5 \\
\hline Colima & 1 & - & 1 \\
\hline Durango & 16 & 1 & 17 \\
\hline Edo. de México & 26 & 8 & 34 \\
\hline Guanajuato & 2 & - & 2 \\
\hline Hidalgo & 6 & 10 & 16 \\
\hline Jalisco & 6 & 9 & 15 \\
\hline Michoacán & 10 & 3 & 13 \\
\hline Nuevo León & 4 & 3 & 7 \\
\hline Puebla & 7 & 4 & 11 \\
\hline Querétaro & 1 & 3 & 4 \\
\hline Quintana Roo & 1 & - & 1 \\
\hline San Luis Potosí & 6 & 3 & 9 \\
\hline Sonora & 8 & 5 & 13 \\
\hline Tabasco & 2 & - & 2 \\
\hline Tamaulipas & 3 & 2 & 5 \\
\hline Tlaxcala & 1 & - & 1 \\
\hline Veracruz & 3 & 2 & 5 \\
\hline Yucatán & 1 & 2 & 3 \\
\hline Zacatecas & 7 & - & 7 \\
\hline Registro en blanco & 57 & 9 & 66 \\
\hline Extranjero & 8 & 21 & 29 \\
\hline
\end{tabular}

La participación de ponentes provenientes de otros países es mínima, aunque se verifica un aumento de una edición a otra (del $2 \%$ al $7 \%$ con respecto al total), sobre todo de participantes de Colombia. En otros casos se trata de estudiantes mexicanos realizando estudios en el extranjero.

Son once instituciones a las que adscribe la mitad de los ponentes del CIECH. A excepción de la Universidad Nacional Autónoma de México y de la Universidad Pedagógica Nacional Unidad Ajusco, todas se ubican en el estado de Chihuahua. Destacan, por supuesto, las instituciones de educación superior pertenecientes al subsistema universitario; sin embargo, no podemos omitir a aquellas instituciones 160 pertenecientes o fuertemente vinculadas a la formación para el magisterio. 


\begin{tabular}{lcccc}
\hline \multicolumn{5}{c}{ Tabla 4. Principales instituciones de los ponentes del CIECH } \\
\hline Institución & $\mathbf{2 0 1 6}$ & $\mathbf{2 0 1 8}$ & Total & $\mathbf{2 0 1 8}$ \\
\hline Centro de Investigación y Docencia & 60 & 22 & 82 & 10.61 \\
\hline Universidad Autónoma de Chihuahua & 32 & 49 & 81 & 10.48 \\
\hline Escuela Normal Profr. Luis Urías Belderráin & 13 & 38 & 51 & 6.60 \\
\hline UPN 83 Parral & 25 & 16 & 41 & 5.30 \\
\hline UPN 81 Chihuahua & 24 & 12 & 36 & 4.66 \\
\hline Universidad Autónoma de Ciudad Juárez Campus & 21 & - & 21 & 2.72 \\
Ciudad Juárez & 16 & 2 & 18 & 2.33 \\
\hline Centro Chihuahuense de Estudios de Posgrado & 11 & 7 & 18 & 2.33 \\
\hline Instituto Tecnológico de Ciudad Jiménez & 8 & 6 & 14 & 1.81 \\
\hline Escuela Normal Rural Ricardo Flores Magón & 7 & 6 & 13 & 1.68 \\
\hline Universidad Nacional Autónoma de México & 7 & 3 & 10 & 1.29 \\
\hline UPN Ajusco & 235 & 153 & 388 & 50.19 \\
\hline Otras instituciones & $2016,2018)$ &
\end{tabular}

Fuente: Elaboración propia, a partir de los datos del Comie $(2016,2018)$.

Finalmente, la tabla 5 muestra la distribución de los ponentes según su cargo u ocupación al momento del registro. De acuerdo con los datos proporcionados, el $\mathrm{CIECH}$ es, en lo fundamental, un congreso de especialistas, con casi la mitad de sus ponentes laborando en instituciones con funciones de investigación y docencia (profesores-investigadores).

Asimismo, y pese a la disminución de ponencias en su última edición, el congreso presenta un crecimiento de estudiantes de licenciatura y doctorado, lo que sugiere la progresiva constitución como un espacio de comunicación entre aspirantes e iniciados (Adler-Lomnitz, 2009). En este sentido, no sería extraño que en un futuro cercano se busque dotar de algo más de formalidad a esa relación mediante iniciativas que se verifican en otros eventos de IE: encuentros de estudiantes de posgrado.

\begin{tabular}{lcccc}
\hline \multicolumn{5}{c}{ Tabla 5. Cargo de los ponentes del CIECH 2016 y 2018} \\
\hline Cargo & $\mathbf{2 0 1 6}$ & $\mathbf{2 0 1 8}$ & Total & $\mathbf{\%}$ \\
\hline Profesor & 82 & 76 & 158 & 20.44 \\
\hline Profesor-investigador & 227 & 143 & 370 & 47.87 \\
\hline Investigador & 12 & 10 & 22 & 2.85 \\
\hline Auxiliar de investigación & 3 & 1 & 4 & 0.52 \\
\hline Estudiante licenciatura & 15 & 34 & 49 & 6.34 \\
\hline Estudiante maestría & 21 & 5 & 26 & 3.36 \\
\hline Estudiante doctorado & 22 & 29 & 51 & 6.60 \\
\hline Funcionario federal & 3 & 1 & 4 & 0.52 \\
\hline Funcionario estatal & 5 & 0 & 5 & 0.65 \\
\hline Otro & 69 & 15 & 84 & 10.87 \\
\hline Total & $\mathbf{4 5 9}$ & $\mathbf{3 1 4}$ & $\mathbf{7 7 3}$ & $\mathbf{1 0 0 . 0 0}$ \\
\hline
\end{tabular}

Fuente: Elaboración propia, a partir de los datos del Comie $(2016,2018)$. 


\section{Coilltoríiss}

La mayoría de las contribuciones del CIECH se presenta en coautoría (66.8 y 70.2) (tabla 6). Se trata de una situación común en lo que a la producción de conocimiento se refiere, y la IE no es la excepción. Una rápida comparación con la última edición del Congreso Nacional de Investigación Educativa (Comie, 2017), en el que se aceptaron poco más de 1400 contribuciones en modalidades similares a las del CIECH, es un ejemplo de que el porcentaje de coautorías no es muy diferente cuando se trata de eventos de dimensiones mayores, pues casi el $60 \%$ de las contribuciones tuvo dos 0 más autores.

Asimismo, 62\% de las coautorías del CIECH en 2016 y 2018 se integraron por tres autores. La situación es particularmente relevante dado que, como podrá observarse más adelante, no todas las colaboraciones suponen relaciones entre instituciones.

Es evidente que, más allá de la colaboración entre autores en una ponencia, los congresos académicos constituyen un fenómeno colectivo que tiene lugar en el seno de una comunidad en particular. Sin embargo, ante una situación en la que las coautorías en la producción científica son la norma antes que la excepción (véase Vinck, 2015), interesa conocer cuáles son los resultados de la agregación de acciones individuales. En este caso, cuáles son los grupos a que dan lugar un evento al que concurren poco más de 500 autores; cuáles son, en suma, los grupos que emergen de sus afinidades electivas.

\section{Nlínowo}

El estudio de redes académicas y de científicos se ha servido, por lo regular, de las citas de publicaciones para establecer la estructura de las relaciones entre los actores involucrados. Por su parte, el estudio de coautorías, escriben Molina, Muñoz y Domenech (2002), constituye un enfoque más o menos reciente, aunque los congresos académicos no han sido, desde esta perspectiva, objeto de un estudio sistemático. Ello a pesar de las sugerencias de Crane (1969) de servirse de la información que de estos deriva para la determinación de los "colegios invisibles".

Trazaré la red de autores a partir de las coautorías del CIECH. Posteriormente, a partir de los datos de afiliación institucional de esos autores, derivaré los vínculos interinstitucionales y endogámicos que se generan en este mismo congreso.

El procedimiento utilizado para derivar redes interinstitucionales a partir de datos de afiliación tiene sus orígenes en el planteamiento de Breiger (1974) sobre la dualidad de los grupos y las personas, y del cual el ARS ha sabido sacar provecho a

\begin{tabular}{lcccccc}
\hline \multicolumn{7}{c}{ Tabla 6. Contribuciones en coautoría, CIECH 2016 y 2018 } \\
\hline \multirow{2}{*}{ Año } & $\begin{array}{c}\text { Contribuciones } \\
\text { aceptadas }\end{array}$ & $\begin{array}{c}\text { Contribuciones } \\
\text { en coautoría (\%) }\end{array}$ & $\begin{array}{c}\mathbf{2} \\
\text { autores }\end{array}$ & $\begin{array}{c}\mathbf{3} \\
\text { autores }\end{array}$ & $\begin{array}{c}\mathbf{4} \text { o } \\
\text { más }\end{array}$ & $\begin{array}{c}\text { Promedio } \\
\text { de autores }\end{array}$ \\
\hline 2016 & 202 & $135(66.8)$ & 39 & 91 & 5 & 2.74 \\
\hline 2018 & 141 & $99(70.2)$ & 39 & 56 & 4 & 2.65 \\
\hline
\end{tabular}

Fuente: Elaboración propia a partir de los datos del Comie $(2016,2018)$. 
partir de los modelos de redes bimodales (Scott, 2013; Wasserman y Faust, 1004). A grandes rasgos, Breiger plantea que si los individuos se relacionan entre sí a partir de su afiliación común a los grupos, estos últimos también están relacionados cuando tienen afiliados comunes.

Con base en lo anterior, consideraré que existe una relación entre dos autores cuando estos colaboran -se solapan- en una contribución. Y lo mismo ocurre con las relaciones interinstitucionales: los autores se afilian a una institución, y si una contribución es producto de una colaboración entre dos o más autores, se considera que hay una relación entre sus instituciones.

En los casos en que los autores pertenezcan a la misma institución, se establecen relaciones entre estos, pero no entre instituciones. Denominaré a esta situación "vínculo endogámico", y aunque la gran mayoría de estos refieren contribuciones en que todos los autores se adscriben a la misma institución, cuando tres autores se afilian a dos instituciones (fig. 1) considero que existe un vínculo endogámico (autores 1-2), pero también dos vínculos interinstitucionales (1-3 y 2-3).

Fig. 1. Relaciones entre autores.

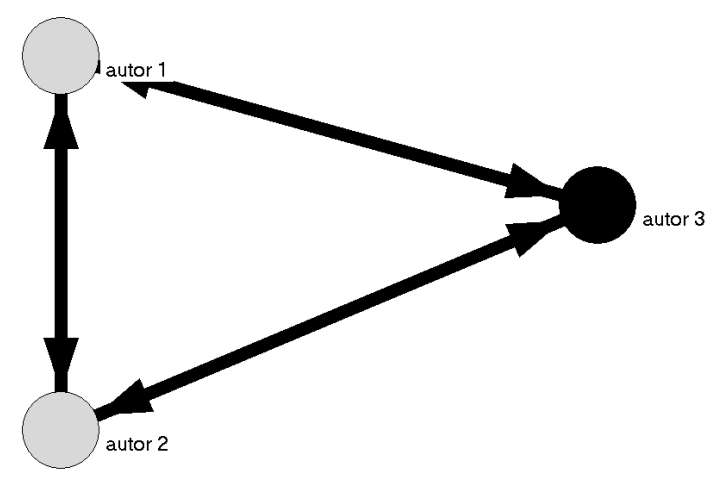

Fuente: Elaboración propia.

Partiré, pues, de los "solapamientos" en las contribuciones de las dos últimas ediciones del CIECH. Iré de las relaciones entre autores a las relaciones entre instituciones, de las afinidades electivas de los académicos, estudiantes y funcionarios que aquí concurren a las relaciones interinstitucionales que surgen a partir de la agregación de las colaboraciones entre autores.

A diferencia de los procedimientos estadísticos para la identificación de grupos (clústeres), el ARS resulta particularmente útil dado que permite visualizar los vínculos entre los nodos de una red (autores e instituciones) y la intensidad de las relaciones que entre estos se establecen.

Dos puntos antes de pasar a los resultados. Los datos utilizados corresponden al SIGECIC. Sin embargo, aunque estos fueron proporcionados por los propios autores, no están exentos de dificultades. Sobre todo, veremos cuando su institución de adscripción no se encontraba en el catálogo al momento del registro.

En segundo lugar, para el trazado de las figuras se utilizó el software Pajek. El tamaño de los nodos se determinó según su grado nodal (Cfr. Freeman, 2000); esto 
es, el número de relaciones -lazos- con que cuenta cada autor o institución dentro de la red y cuyos nombres no se omitieron. El grosor de las líneas está determinado por la intensidad de los vínculos.

\section{Resititinos}

\section{Litores}

Las figuras 1 y 2 muestran la red de autores a que dan lugar las coautorías del CIECH en 2016 y 2018. Como puede observarse, no se trata de redes conexas, sino que estas se integran por varios componentes no relacionados entre sí. Aquí me ocuparé de los más importantes; sin embargo, cabe destacar que la disminución en el número de contribuciones señalada en el apartado anterior impactó en su número y composición.

Cada componente cuenta con uno o dos autores con el mayor grado nodal debido a su coautoría en distintas contribuciones del congreso. Y aunque estos actores centrales presenten contribuciones solo en un área temática, los nodos con que se relacionan en segundo grado o más suelen participar en hasta tres áreas diferentes, lo que permite afirmar que los componentes principales de la red, vale decir, los grupos fuertes de la investigación educativa en el estado, no se articulan en torno a la segmentación temática del CIECH, pues no son un reflejo de esta.

Una posible lectura es que si bien esos grupos se originan en las disciplinas 0 dominios temáticos de sus líderes (los actores centrales), su influencia se ha ido extendiendo más allá de estos. Empero, solo una aproximación empírica al campo de la investigación educativa en Chihuahua permitiría identificar los mecanismos mediante los cuales se construye el poder y reconocimiento académicos.

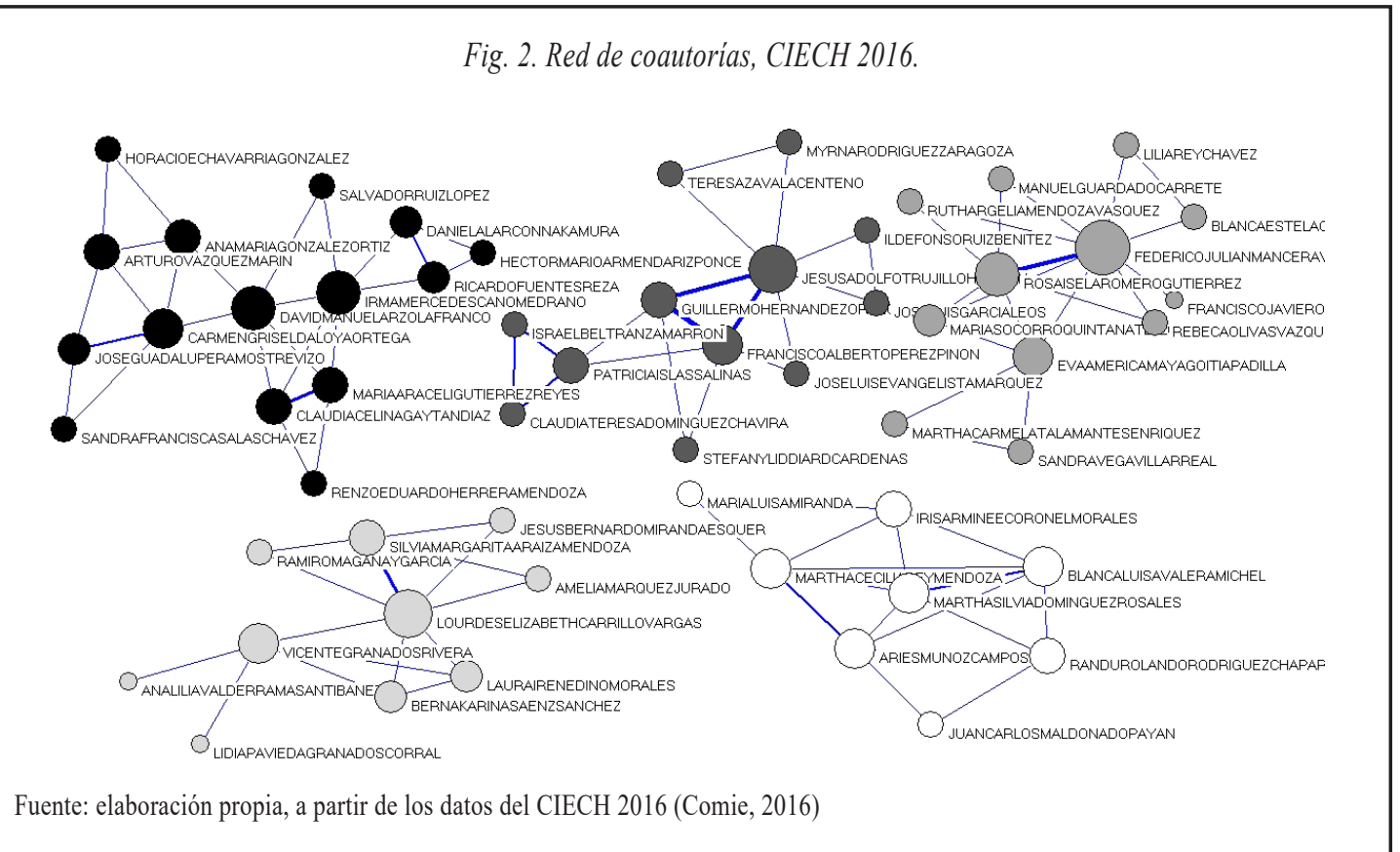


El grueso de las relaciones de coautoría tiene una intensidad igual a 1, pues la colaboración se da solo en una contribución. Las gráficas 3 y 4 muestran las colaboraciones que se presentan en más de tres casos. Puede observarse que además de involucrar a unos cuantos autores, solo tres de ellos se mantienen de una edición a otra. En todos los casos sus contribuciones se presentan en el área 1, y en particular en la subárea de historia e historiografía de la educación.

A este respecto, es probable que, como señalaba el presentador a un libro de uno de estos autores, "uno de los grupos más activos de la educación en México es el de Chihuahua" (Camargo, 2014). Aunque, por supuesto, solo un análisis comparativo podría determinar la posición que este grupo ocupa en el conjunto de la investigación educativa nacional. Volveré sobre este punto en el siguiente apartado.

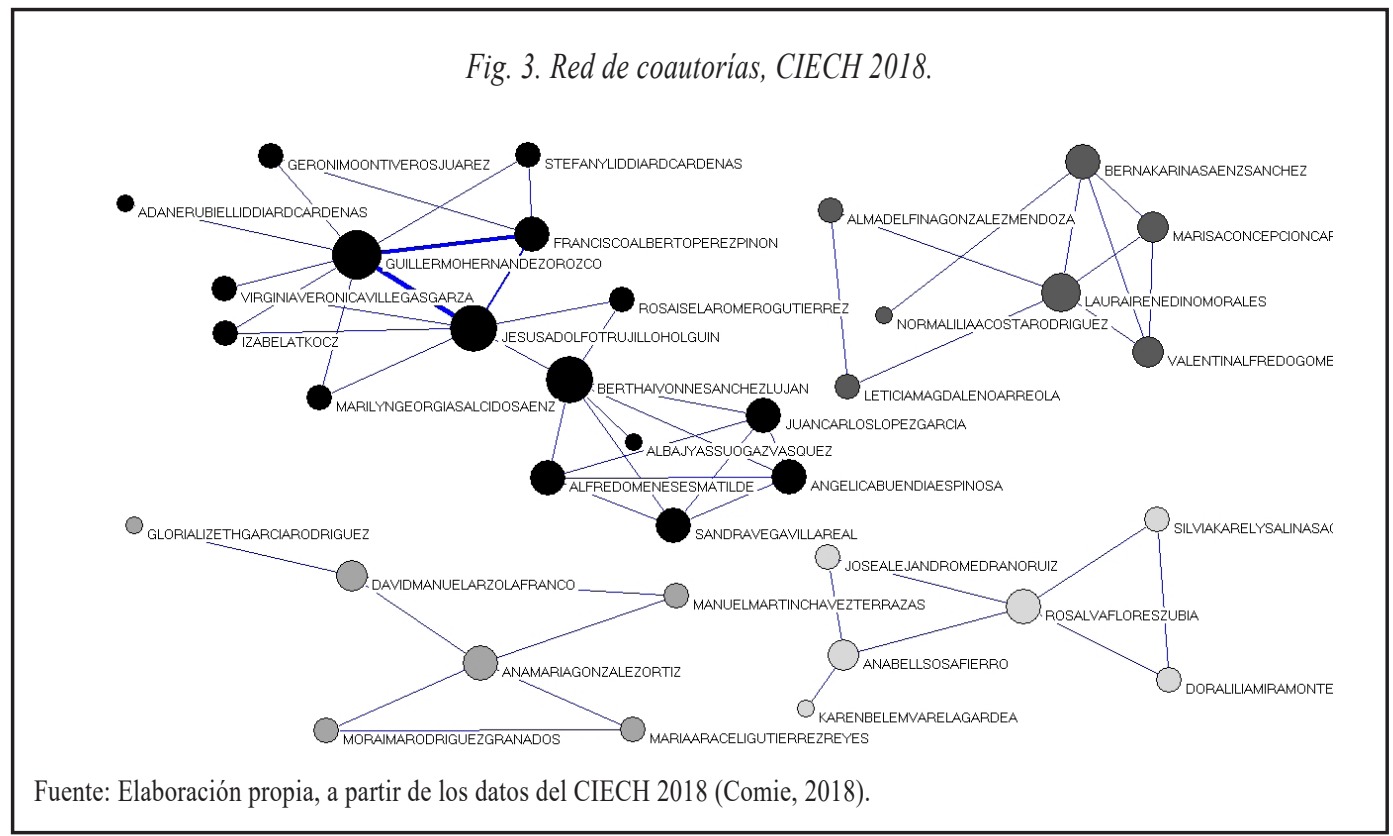

Fig. 4. Relaciones de mayor intensidad, CIECH 2016.

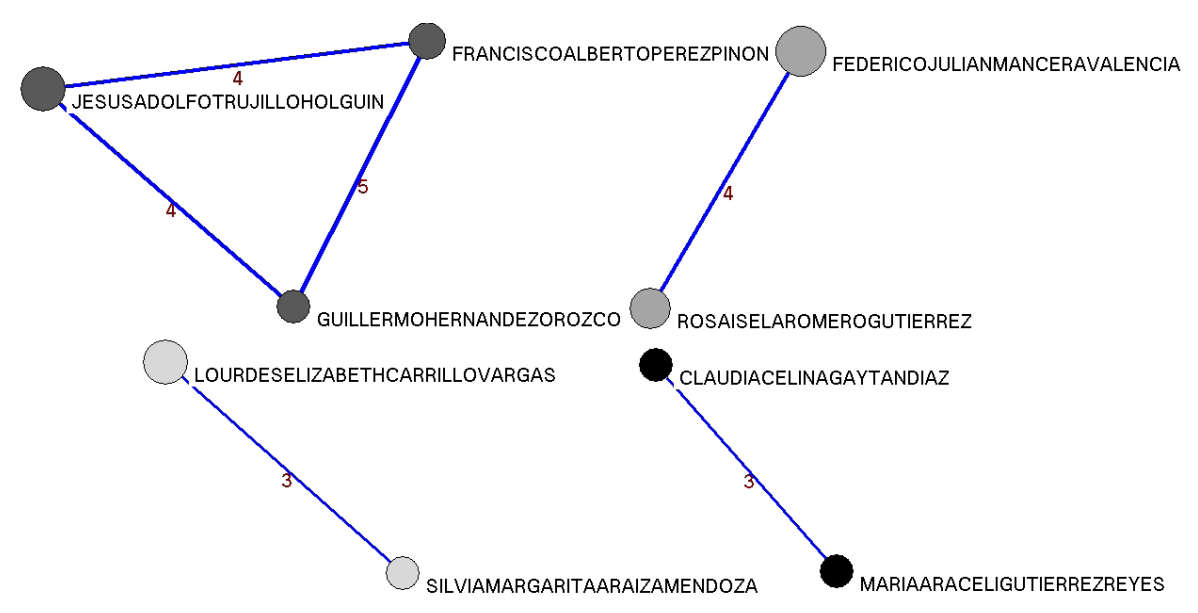

Fuente: Elaboración propia. con base en los datos del CIECH 2016 (Comie. 2016). 
El resto de las relaciones de mayor intensidad, todas ellas de tipo diádico, se presentan en las áreas 2,3 y 5.

\section{Relaciones interinstitucioniles}

Las figuras 7 y 8 presentan las redes interinstitucionales de las dos últimas ediciones del CIECH. Para su elaboración se consideró la institución de afiliación de los coautores. En caso de que esta no se encontrase en el catálogo, los ponentes marcaban la opción "otra", la cual se ve precedida en las figuras de la abreviación de la entidad federativa inicialmente marcada por ellos mismos (ch Otra).

En comparación con la red de autores, las relaciones interinstitucionales presentan algunas especificidades. El número de componentes es mucho menor, pues los autores se afilian a un conjunto relativamente pequeño de instituciones. Tanto en 2016 como en 2018 destaca un componente principal conformado en su mayoría por instituciones del estado de Chihuahua y a las que se afilian prácticamente todos los autores arriba identificados. Algunas de esas instituciones ocupan posiciones centrales o juegan un importante papel de intermediación en la red.

Asimismo, aunque aquí me abocaré solo al componente principal, destaca la presencia de varios nodos aislados y sin conexiones. Esto debido a que una parte considerable de las coautorías se da entre autores de la misma institución, consecuencia de una suerte de "endogamia académica" sobre la que volveré más adelante.

La diferenciación de nodos mediante la escala de grises sugiere algunos clústeres institucionales a partir de la intensidad de las relaciones de coautoría. Sin embargo, más allá de las particularidades que llevan a una institución a ocupar una determinada posición en la red y agruparse con otras, señalaré lo que parece ser una reconfiguración de las relaciones interinstitucionales en el CIECH de una edición a otra.

Dos puntos sugieren este proceso: la disminución de instituciones pertenecientes o fuertemente ligadas al sector magisterial (escuelas normales y unidades de la UPN) y la reconfiguración de los vínculos de aquellas que, también pertenecientes o

Fig. 6. Relaciones interinstitucionales, CIECH 2016.

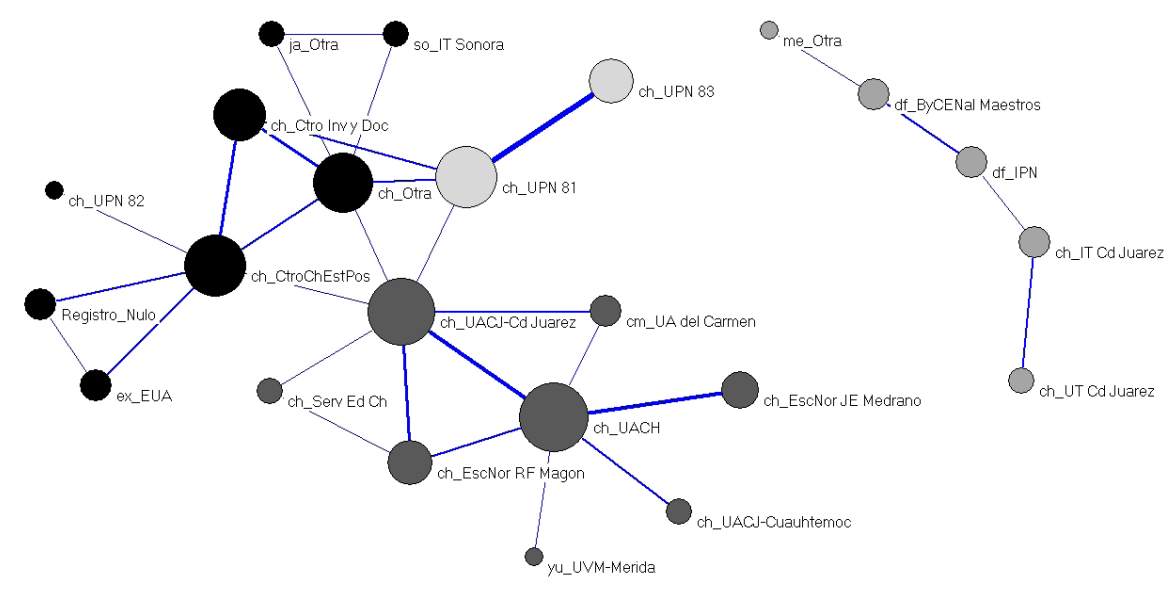

Fuente: Elaboración propia, con base en los datos del CIECH 2016 (Comie, 2016). 
Fig. 7. Relaciones interinstitucionales, CIECH 2018.

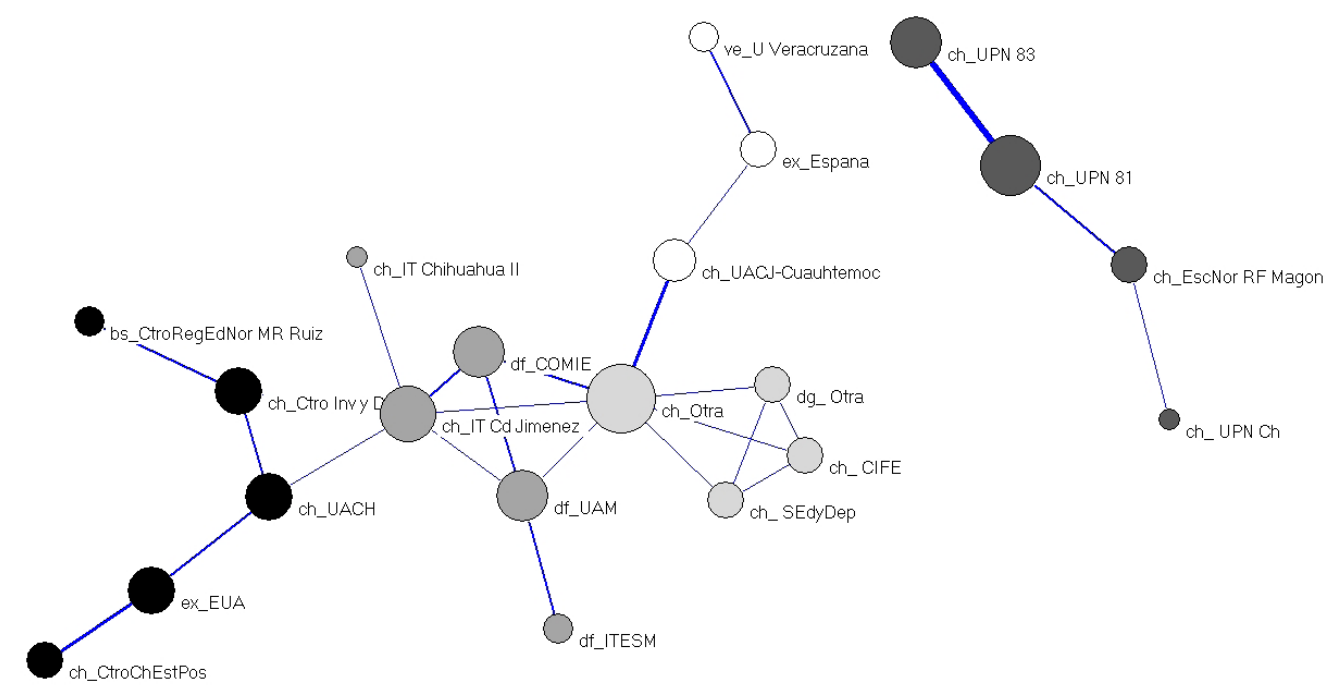

Fuente: Elaboración propia, con base en los datos del CIECH 2018 (Comie, 2018).

ligadas a ese sector, se mantuvieron en el componente principal de la red, sea a partir de la disminución en su grado nodal -como en los casos del Centro de Investigación y Docencia y del Centro Chihuahuense de Estudios de Posgrado- o mediante el establecimiento de vínculos solo entre este tipo de instituciones, como en la triada entre la Secretaría de Educación y Deporte del Estado, el CIFE y una institución del estado de Durango (gráfica 9).

Empero, más allá de los cambios en los vínculos interinstitucionales y del inconveniente de que para su confirmación supone el nodo "otra institución", destaca el hecho de que, en comparación con estos, las relaciones que derivan de las coautorías entre personas afiliadas a la misma institución tienen, en algunos casos, un peso mayor. Me referiré a estas en el próximo apartado.

\section{Sobre la "endoganinilia ictidlémiciai"}

A falta de un mejor término, denominaré a la relación de coautoría entre personas de una misma institución como "vínculo endogámico". Aunque el estudio de la endogamia académica (academic inbreeding) se ha enfocado casi exclusivamente en la contratación, por parte de las IES, de sus propios graduados (Altbach, Yudkevich y Rumbley, 2015), una mirada relacional se justifica no solo por un contexto en el que el trabajo académico es, cada vez en menor medida, el producto de hombres aislados, sino también por las dinámicas sociales a que da lugar ese contexto. No ahondaré sobre este punto, pero piénsese, por ejemplo, en cómo una determinada política educativa puede incentivar o no las relaciones intra e interinstitucionales.

Un par de cuestiones antes de abordar los vínculos endogámicos. La información disponible no permite hacer afirmaciones precisas, ya que la adscripción de los autores refiere solo a su institución, y en algunos casos a sedes específicas, pero no a 
unidades más pequeñas, como facultades o departamentos académicos. Bien puede suceder que lo que aquí se considera como un vínculo endogámico en realidad sea una colaboración más compleja; entre los departamentos de salud y educación, por ejemplo.

También señalé las particularidades de las contribuciones en que tres autores se adscriben a dos diferentes instituciones (figura 1), lo que supone tanto vínculos interinstitucionales como endogámicos. Las diferencias entre ambos pueden observarse en la tabla 7, aunque se muestran solo las instituciones con el mayor grado nodal de las dos últimas ediciones del CIECH, todas ellas del estado de Chihuahua.

Dicho lo anterior, el peso de los vínculos endogámicos contrasta con los interinstitucionales. En algunos casos, concretamente el Centro de Investigación y Docencia y la Universidad Autónoma de Chihuahua, estos representan más del $70 \%$ del total de las relaciones derivadas de las coautorías del CIECH (tabla 7). De hecho, las relaciones más intensas entre autores arriba apuntadas (figuras 4 y 5 ) refieren, en su totalidad, lazos de este tipo.

Fig. 5. Relaciones de mayor intensidad, CIECH 2018.

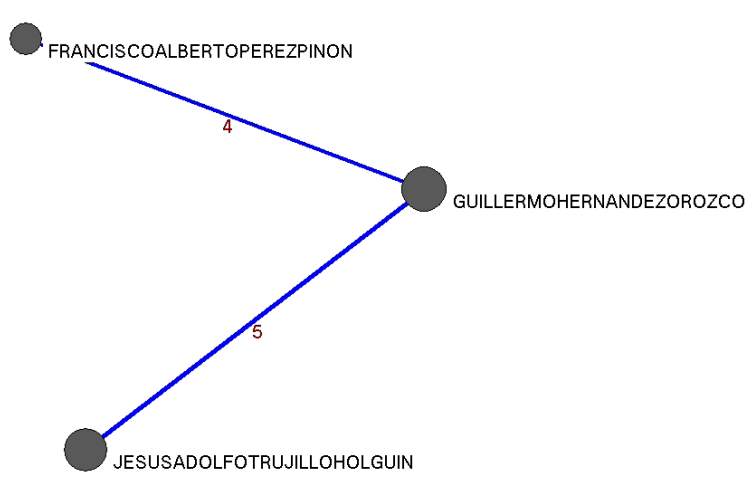

Fuente: Elaboración propia, con base en los datos del CIECH 2018 (Comie, 2018).

Empero, cometeríamos un error al considerar a los vínculos endogámicos como algo negativo. Desde una perspectiva de redes, estos pueden suponer redundancia en la información (véase Granovetter, 1973), pero hablamos de procesos algo más complejos en los que la endogamia refiere condiciones históricas específicas y, en algunos casos, llega a constituir la fuerza de un grupo con respecto otros que integran el campo de la IE en México.

En cualquier caso, es importante apuntar el contraste entre la variación de los vínculos interinstitucionales y la intensidad de los lazos endogámicos. Me permito adelantar una hipótesis sobre este punto, pero que, sin embargo, no podré corroborar. Si atendemos la estructura de las redes interinstitucionales, y en particular a las instituciones centrales de los principales componentes de ambas ediciones, podemos decir que mientras los lazos interinstitucionales parecen depender de circunstancias coyunturales, como la sede del CIECH o la estructura de la Red de Investigadores Educativos Chihuahua (Rediech), principal organizadora del evento, los lazos endogámicos sugieren, me parece, afinidades algo más duraderas en el ámbito de la IE estatal. Volveré sobre este punto en el último apartado. 


\begin{tabular}{|c|c|c|c|c|c|}
\hline \multirow{2}{*}{ Institución } & \multicolumn{2}{|c|}{2016} & \multicolumn{2}{|c|}{2018} & \multirow{2}{*}{$\begin{array}{c}\text { Lazos } \\
\text { endogámicos } \\
(\%)\end{array}$} \\
\hline & Inter & Endo & Inter & Endo & \\
\hline Centro de Investigación y Docencia & 8 & 38 & 5 & 11 & $49(79.0)$ \\
\hline Universidad Autónoma de Chihuahua & 14 & 18 & 5 & 28 & $46(70.8)$ \\
\hline Universidad Pedagógica Nacional 83 & 6 & 14 & 6 & 5 & $19(61.3)$ \\
\hline Universidad Pedagógica Nacional 81 & 11 & 14 & 8 & 3 & $17(47.2)$ \\
\hline $\begin{array}{l}\text { Universidad Autónoma de Ciudad Juárez } \\
\text { Campus Cd. Juárez }\end{array}$ & 13 & 11 & 2 & 2 & $13(46.4)$ \\
\hline $\begin{array}{l}\text { Centro Chihuahuense de Estudios de } \\
\text { Posgrado }\end{array}$ & 11 & 8 & 3 & 0 & $8(36.4)$ \\
\hline Escuela Normal Ricardo Flores Magón & 6 & 6 & 3 & 2 & $8(47.1)$ \\
\hline Instituto Tecnológico de Ciudad Jiménez & 2 & 6 & 7 & 2 & $8(47.1)$ \\
\hline $\begin{array}{l}\text { Universidad Autónoma de Ciudad Juárez } \\
\text { Campus Cuauhtémoc }\end{array}$ & 2 & 4 & 4 & 2 & $6(50.0)$ \\
\hline Escuela Normal Superior José E. Medrano & 4 & 4 & 0 & 0 & $4(50.0)$ \\
\hline
\end{tabular}

Fuente: Elaboración propia, a partir de los datos del Comie $(2016,2018)$.

\section{A NIIERI DE OIERRE}

Las coautorías ocupan un porcentaje importante en las publicaciones académicas: "La parte de artículos firmados por una sola persona se reduce a la mitad entre 1920 y 1950, mientras que el número de trabajos cofirmados por al menos cuatro investigadores no cesa de aumentar" (Vinck, 2015, p. 29). Sin embargo, solo en la última década su estudio ha comenzado a adquirir relevancia (Molina, Muñoz y Domenech, 2002).

Aquí he abordado las coautorías de un congreso académico en el campo de la IE con el objetivo de averiguar si la agregación de decisiones individuales -la de presentar una ponencia con un determinado par, y no con otro- genera grupos tanto de autores como de las instituciones a las que estos se afilian. El ARS, señalé, constituye una herramienta privilegiada, pues si bien algunos de los grupos aquí identificados pueden intuirse en la práctica (al menos para quienes forman parte del campo de la IE en el estado), el enfoque reticular proporciona una mirada panorámica que permite ver más allá de nuestro círculo inmediato (véase: Kadushin, 2013).

Así, además de los principales grupos de autores, las relaciones de mayor intensidad entre estos y las relaciones interinstitucionales a que da lugar la afiliación institucional a lo largo del artículo se constataron tres puntos:

1. Los principales grupos de la IE del estado no se articulan en torno a una determinada área temática, pues aun cuando sus autores centrales presentan trabajos solo en una de estas, aquellos con quienes se vinculan en segundo y tercer grado suelen hacerlo hasta en dos áreas distintas.

2. Tanto el análisis de coautorías como la derivación de las relaciones interinstitucionales a partir de la afiliación de los autores permitió constatar que la mayoría de estos no solo se adscribe a un pequeño número de instituciones, sino que las relaciones de mayor intensidad corresponden a autores de una misma institución. 
Denominé a esta circunstancia como "lazos endogámicos", y en términos institucionales estos son igual o más fuertes que las relaciones interinstitucionales.

3. Las relaciones interinstitucionales cambian de una edición a otra, por lo que sugerí que estas podían depender de factores coyunturales. Me referí a la sede del CIECH y la estructura interna de la Rediech, dadas las instituciones con el mayor grado nodal; sin embargo, aún falta averiguar qué otros factores influyen en las prácticas de asociación y publicación en los congresos académicos. Piénsese, por ejemplo, en cómo la evaluación ligada a estímulos económicos extraordinarios ha modificado nuestras afinidades electivas.

En general, los "hallazgos" del artículo refieren tensiones profundas que se verifican en la base del trabajo académico: las fronteras temáticas o disciplinares y las de tipo institucional; tensiones que, por lo demás, refieren las fuerzas centrífugas y centrípetas advertidas por Clark (1991), a propósito de los sistemas de educación superior y a las que la IE no es indiferente.

En este sentido, la identificación de grupos mediante las técnicas del ARS constituye apenas el primer paso para arribar hacia un enfoque relacional de la IE en México. ¿Cómo se configuran las comunidades en este particular ámbito de investigación? ¿Cuáles son los mecanismos que se ponen en marcha para dar lugar a los dos tipos de relaciones (inter e intrainstitucionales) que se verificaron en las figuras a lo largo de este artículo? ¿Presentan otros congresos una morfología similar a la que deriva de las coautorías del CIECH? ¿Qué factores determinan esa morfología?

Se trata de preguntas que, si bien suponen enfoques diferenciados, y hasta contrapuesto, han sido planteadas gracias al ARS, pues este no solo posibilita la generación de mapas y métricas otrora inexistentes, sino que, a partir suyo, el investigador puede hacer inmersiones en un territorio nuevo: el que emerge de manera imprevista e incontrolada a partir de las relaciones sociales.

\section{ReFRerevills}

Adler-Lomnitz, L. (2009). El congreso científico como forma de comunicación. En N.G. Gutiérrez Serrano (coord.), Redes, comunidades, grupos y trabajo entre pares en la investigación educativa. México: CRIM / UNAM, Plaza y Valdés.

Altbach, Ph., Yudkevich, M. y Rumbley, L.E. (2015). Academic inbreeding: Local challenge, global problem. Asia Pacific Education Review, 16(3), 317-330.

Breiger, R.L. (1974). The duality of persons and groups. Social Forces, 53(2), 181-190.

Clark, B. (1991). El sistema de educación superior. Una visión comparativa de la organización académica. México: Nueva Imagen, Universidad Futura, UAM Azcapotzalco.

Camargo, S. (2014). Prólogo. En J.A. Trujillo Holguín (coord.), Miradas históricas a la formación del profesorado en Chihuahua. Chihuahua: Doble Hélice Ediciones.

Comie. (2016). Sistema Integral de Gestión de Conocimiento e Información del Comie SIGECIC: Tercer Congreso de Investigación Educativa en Chihuahua [base de datos]. Recuperado de www.comie.org.

Comie. (2017). XIV Congreso Nacional de Investigación Educativa. Cifras básicas. Revista Mexicana de Investigación Educativa, 22(75), 1323-1330.

Comie. (2018). Sistema Integral de Gestión de Conocimiento e Información del COMIE SIGECIC: IV Congreso de Investigación Educativa en Chihuahua [base de datos]. Recuperado de www. comie.org. 
Crane, D. (1969). Social structure in a group of scientists: A test of the "invisible college" hypothesis. American Sociological Review, 34(3), 335-352.

Freeman, L. (2000). La centralidad en las redes sociales. Clarificación conceptual. Política y Sociedad, (33), 131-148.

Granovetter, M. (1973). The strength of weak ties. American Journal of Sociology, 78(6), 13601380.

Gutiérrez Serrano, N.G. (2009). Comunidades especializadas en investigación educativa y producción de conocimiento. En N.G. Gutiérrez Serrano (coord.), Redes, comunidades, grupos y trabajo entre pares en la investigación educativa. México: CRIM / UNAM, Plaza y Valdés.

Gutiérrez Serrano, N.G. (2014). Producción de conocimiento y formación de investigadores. Sinéctica, (43).

Kadushin, Ch. (2013). Comprender las redes sociales. Teorias, conceptos y hallazgos. Madrid: Centro de Investigaciones Sociológicas.

Martínez Rizo, F. (1996). La investigación educativa en México en el contexto latinoamericana. En G. de Landsheere, La investigación educativa en el mundo: con un capítulo especial sobre México. México: Fondo de Cultura Económica.

Molina, J.L., Muñoz, J.M. y Domenech, M. (2002). Redes de publicaciones científicas: un análisis de coautorías. REDES. Revista hispana para el análisis de redes sociales, 1(3).

OECD-CERI (2004). Revisión nacional de investigación y desarrollo educativos. Reporte de los examinadores sobre México. Revista Mexicana de Investigación Educativa, 14(21), 515-550.

Ramírez, R. y Weiss, E. (2004). Los investigadores educativos en México: una aproximación. Revista Mexicana de Investigación Educativa, 14(21), 501-513.

Rediech. (2018). Convocatoria del IV Congreso Internacional de Investigación Educativa en Chihuahua. Recuperado de http://www.rediech.org/inicio/index.php

Scott, J. (2013). Social network analysis ( $3^{\mathrm{a}}$ ed.). Londres: Sage.

Vinck, D. (2015). Ciencia y sociedad. Sociología del trabajo científico. Barcelona: Gedisa.

Wasserman, S. y Faust, K. (1994). Social network analysis: Methods and applications. Nueva York: Cambridge University Press.

\section{LGReIDECIIIENTOS}

Este artículo se basa en una presentación realizada para una conversación educativa en el IV Congreso Internacional de Investigación Educativa en Chihuahua el 12 de octubre de 2018 en la Universidad Autónoma de Chihuahua. El autor agradece al Consejo Mexicano de Investigación Educativa (Comie) el apoyo brindado durante el periodo en que se desempeñó como responsable del Área de Gestión y Análisis de Información de este mismo Consejo, así como a la Red de Investigadores Educativos Chihuahua (Rediech) por la invitación al evento. 
